\title{
How is female mate choice affected by male competition?
}

\author{
Bob B. M. Wong ${ }^{1,2,3 *}$ and Ulrika Candolin ${ }^{3}$ \\ ${ }^{1}$ School of Botany and Zoology, Australian National University, Canberra, ACT 0200, Australia \\ ${ }^{2}$ Boston University Marine Program, 7 MBL Street, Woods Hole, MA 02543, USA \\ ${ }^{3}$ Department of Biological and Environmental Sciences, University of Helsinki, P.O. Box 65, Helsinki, FIN-00014, Finland
}

(Received 26 October 2004; revised 21 March 2005; accepted 23 March 2005)

\begin{abstract}
The plethora of studies devoted to the topics of male competition and female mate choice belie the fact that their interaction remains poorly understood. Indeed, on the question of whether competition should help or hinder the choice process, opinions scattered throughout the sexual selection literature seem unnecessarily polarised. We argue, in the light of recent theoretical and empirical advances, that the effect of competition on mate choice depends on whether it results in the choosy sex attaining high breeding value for total fitness, considering both direct and indirect fitness benefits. Specifically, trade-offs may occur between different fitness benefits if some are correlated with male competitive ability whilst others are not. Moreover, the costs and benefits of mating with competitive males may vary in time and/or space. These considerations highlight the importance of injecting a life-history perspective into sexual selection studies. Within this context, we turn to the sexual selection literature to try to offer insights into the circumstances when competition might be expected to have positive or negative implications for pre-copulatory female choice. In this regard, we elaborate on three stages where competition might impact upon the choice process: (i) during mate detection, (ii) mate evaluation, and (iii) in dictating actual mating outcomes. We conclude by offering researchers several potentially rewarding avenues for future research.
\end{abstract}

Key words: courtship disruption, eavesdropping, fitness, mate detection, mate evaluation, mating outcome, sexual conflict, sexual selection, signal honesty.

\section{CONTENTS}

I. Introduction

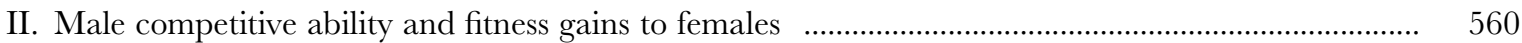

III. Role of competition in mate detection ................................................................................... 561

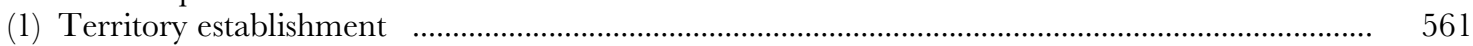

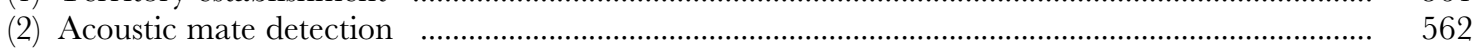

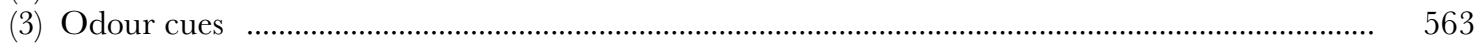

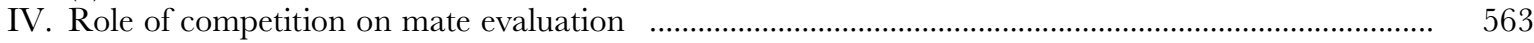

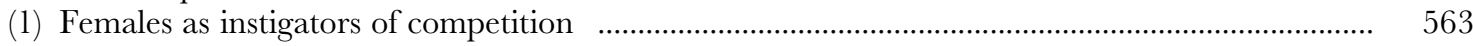

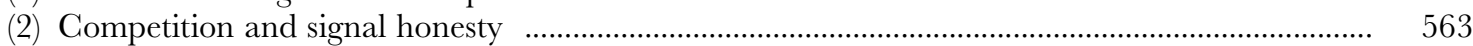

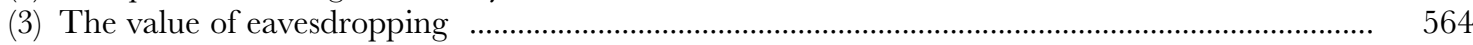

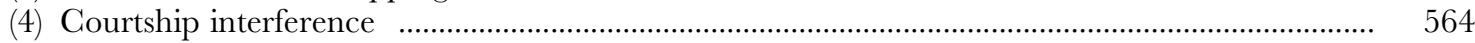

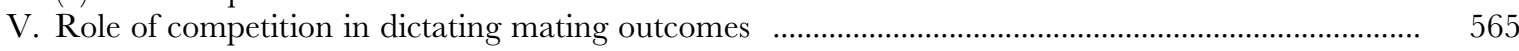

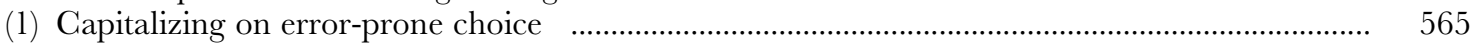

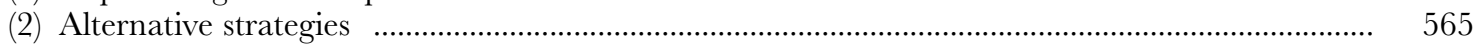

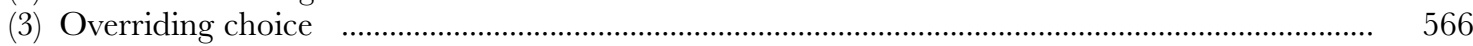

* Address for correspondence: Tel: +358 91915 7810; Fax: +358 91915 7694; E-mail: bob.wong@helsinki.fi 


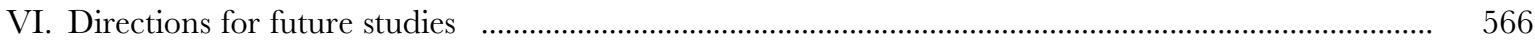

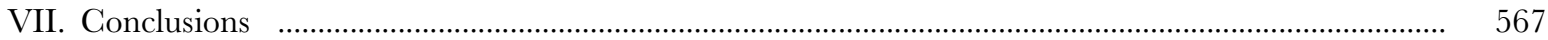

VIII. Acknowledgements ............................................................................................................... 567

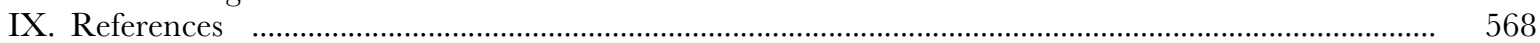

\section{INTRODUGTION}

Certain males often enjoy a mating advantage over others. This differential mating success results from two important mechanisms: male-male competition and female mate choice. Although both mechanisms of sexual selection have each been the focus of considerable research, a unified understanding of how they interact remains elusive (Qvarnström \& Forsgren, 1998). Competitive interactions between rival males are likely to impact upon female choice, but will this impact be positive or negative? Does competition help or hinder the mate choice process?

Opinion, scattered throughout the vast sexual selection literature, seems polarised. On the one hand, the two main components of sexual selection have traditionally been viewed as 'complementary' in their effects and are frequently said to operate through a process of 'mutual reinforcement' (Berglund, Bisazza \& Pilastro, 1996; Wiley \& Poston, 1996). Under this view, competitive interactions between rival males are seen as beneficial for females. This is because dominant males, which are generally regarded as highquality suitors, are often able to exclude inferior subordinates so that females end up mating with the 'best' males. On the other hand, insights from studies of sexual conflict suggest that competition need not facilitate mate choice (Moore \& Moore, 1999; Moore et al., 2001). A male that is adept in competition may increase his own mating opportunities by excluding rivals (Andersson et al., 2002) and this may occur even if his actions reduce female fitness (Reale, Bousses \& Chapuis, 1996; Holland \& Rice, 1999; Byrne \& Roberts, 2000; Mühlhäuser \& Blankenhorn, 2002; Sih, Lauer \& Krupa, 2002).

Is it possible to reconcile these apparently dichotomous views concerning the effect of competition on mate choice? The answer, we believe, is 'yes'. Evidence indicates that competition can have both positive (Candolin, 1999 a, 2000; Doutrelant \& McGregor, 2000; Berglund \& Rosenqvist, 2001; Ophir \& Galef, 2003) as well as negative (Howard, Moorman \& Whiteman, 1997; Kangas \& Lindström, 2001; Wong, 2004a) implications for adaptive female choice. The purpose of our review is to try to stimulate discussion by providing insights into the circumstances under which competition might be expected to help, as well as hinder, the mate choice process.

\section{MALE GOMPETITIVE ABILITY AND FITNESS GAINS TO FEMALES}

Competition among potential suitors is expected to facilitate female choice if it produces a mating outcome that is consonant with net fitness gains to females. Mate choice can present choosy individuals with both direct material gains that increase their fecundity and/or survival, as well as indirect genetic benefits that improve offspring viability and/ or attractiveness. Competitive ability may correlate with some of these benefits if, for example, males that are adept in competition also monopolise the best resources or territories required by females for breeding as in red-collared widowbirds, Euplectes ardens (Andersson et al., 2002). Moreover, dominance could correlate with genetic benefits if sons inherit their father's competitive prowess, resulting in dominant males siring successful sons (Montgomerie \& Thornhill, 1989; Alatalo, Höglund \& Lundberg, 1991). An example of this is the cockroach, Nauphoeta cinerea, where dominant males that are able to circumvent female choice also sire dominant offspring that may be equally successful at mating (Moore, 1990).

However, although females could receive some benefits from mating with males that are successful in competition, such males may not necessarily guarantee the highest net benefits for females (Wong, 2004b). While certain benefits may be correlated with male competitive ability, others may not (Qvarnström \& Forsgren, 1998). In the sand goby, Pomatoschistus minutus, for instance, dominant males are poor fathers (Forsgren, 1997), although they are successful in obtaining and defending nests of high quality (Lindström, 1992). In seeking to obtain high breeding value for total fitness, any benefits obtained by females from mating with males based on their competitive abilities may, in fact, need to be traded against other components of female fitness (Møller \& Thornhill, 1998; Cordero \& Eberhard, 2003; Kokko et al., 2003; Ophir \& Galef, 2003). When selecting a mate, individuals should, after all, strive to maximise total fitness (Kokko et al., 2003).

A trade-off between direct and indirect benefits of mating with competitive males has been reported in several bird species (Birkhead, 1998; Møller \& Thornhill, 1998;Wright, 1998; Forstmeier et al., 2002; Griffith, Owens \& Thuman, 2002). In those species, females obtain indirect benefit by choosing attractive males to sire their offspring but must increase their own parental effort to compensate for reduced male provisioning. In guppies, Poecilia reticulata, Brooks (2000) found a genetic trade-off between the inheritance of genes that increase offspring attractiveness and viability so that sexy sons sired by attractive males also had shorter lifespans (see also Hine et al., 2002). Recently, examples of ontogenetic conflict have been revealed in Drosophila melanogaster and red flour beetles, Tribolium castaneum, where genomes that increase offspring fitness in one sex reduce offspring fitness in the other (Chippindale, Gibson \& Rice, 2001; Pai \& Yan, 2002). Females may also have to trade any benefits gained from mating with particular males against the risk of 
Table 1. How competition affects female choice

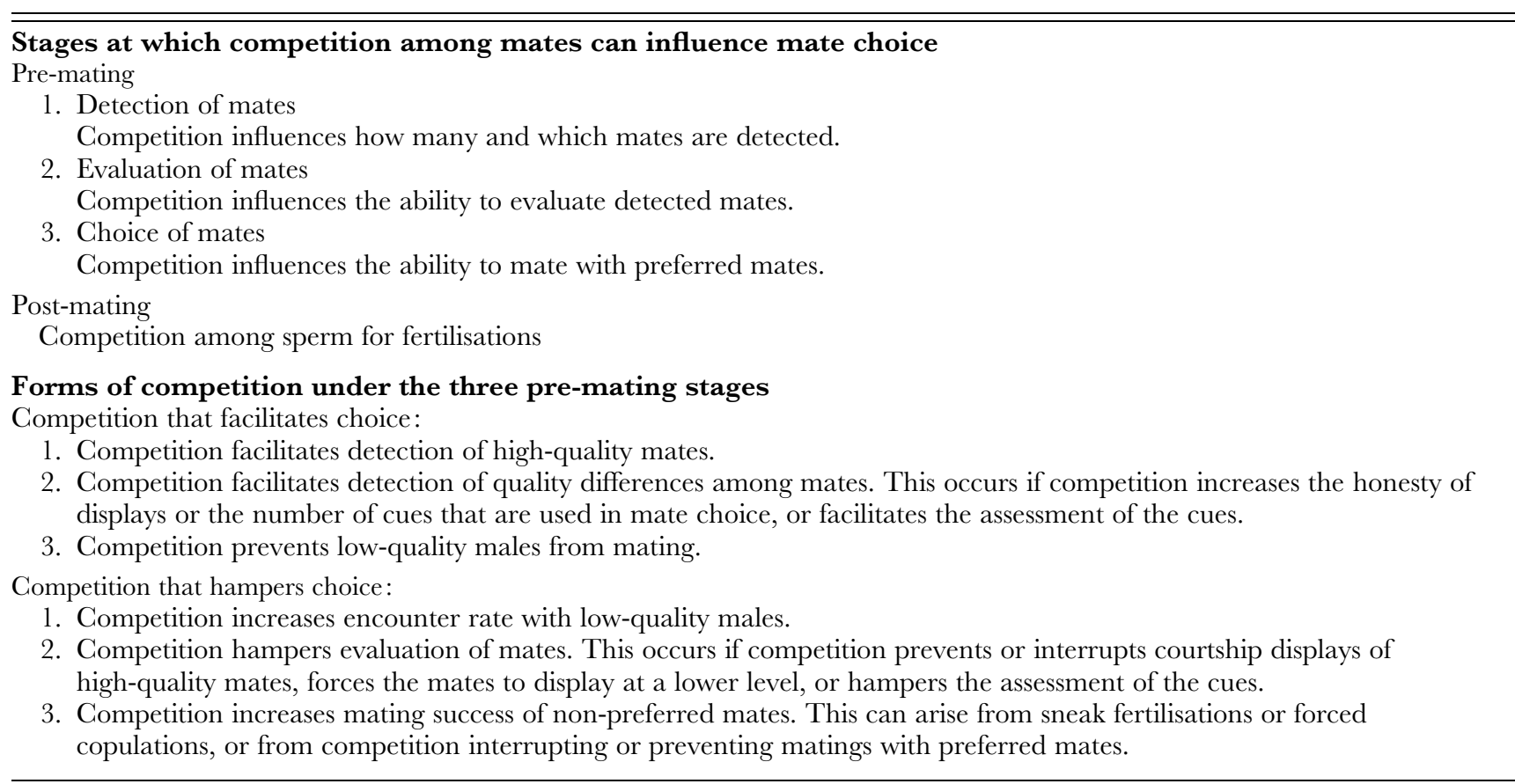

harm that may be incurred (Ophir \& Galef, 2003). Males, in their pursuit of matings, may increase their own reproductive fitness even if it reduces female survival and/or fecundity (Chapman et al., 1995; Holland \& Rice, 1999; Civetta \& Clark, 2000; Friberg \& Arnqvist, 2003). It is important to keep in mind, however, that females 'harmed' in this way, may still acquire genetic benefits if mating success is inherited by their male offspring. Consequently, depending on the net fitness gains to females, competition may still facilitate choice even if, prima facie, females suffer a direct 'cost'.

The magnitude of any beneficial or harmful effects that certain males may have on female fitness may also vary in time and/or space if environmental conditions or intrinsic properties of the individuals change. Several studies have shown, for instance, that male investment in competition and parental care can vary over the course of the reproductive season or over an individual's lifetime (Qvarnström, 1999; Candolin, 2000; Griffith \& Sheldon, 2001; Engqvist \& Sauer, 2002; Badyaev \& Duckworth, 2003; Torok, Hegyi \& Garamszegi, 2003; Duckworth, Mendonça \& Hill, 2004), or between populations (Badyaev \& Hill, 2002; Hegyi, Torok \& Toth, 2002). And because sperm can be limiting (Galvani \& Johnstone, 1998), a competitive male with a high mating rate could represent a poor choice for subsequent females if he ends up delivering lower fertilisation success due to sperm depletion (Warner et al., 1995). Hence, the same male that brings a high fitness return for a female in one context may be a poor suitor in another. These variables are important in guiding female mating decisions and go to the heart of the issue of whether competition should facilitate or hamper female choice.

Having provided a context for our discussion, we now proceed to review how competition might play a role at different stages of the mate choice process. In this regard we acknowledge that male competition can influence female choice before and after mating. In this paper, however, we will focus on pre-copulatory mate choice (for a review of issues pertaining to competition and post-copulatory choice, see Simmons, 2001). Here, we identify three key opportunities where intrasexual competition might have an impact on females: (1) during detection of mates, (2) during the mate assessment (or evaluation) process, and (3) in dictating actual mating outcomes (Table 1). Finally, we conclude by offering suggestions on how researchers might be able to integrate some of the issues raised in this review into their own research programs.

\section{ROLE OF GOMPETITION IN MATE DETEGTION}

\section{(1) Territory establishment}

Competition could facilitate choice by excluding inferior males so that only the very best males can be detected, or it could hamper choice by excluding males that females may otherwise prefer. An obvious way in which competition could affect mate detection is by influencing which males establish territories, when and where these territories are established, and/or the size of the territories. For example, in the red-shouldered widowbird, Euplectes axillaris, males with larger and redder epaulettes have higher intrinsic resource-holding potential than subdominant males and establish territories to the exclusion of males with smaller signals that are less red (Pryke \& Andersson, $2003 a, b$ ). An effect of territory quality on mate encounter rate has been demonstrated in the threespine stickleback, Gasterosteus 
Table 2. Fitness benefits and costs of mating with the winners of contests

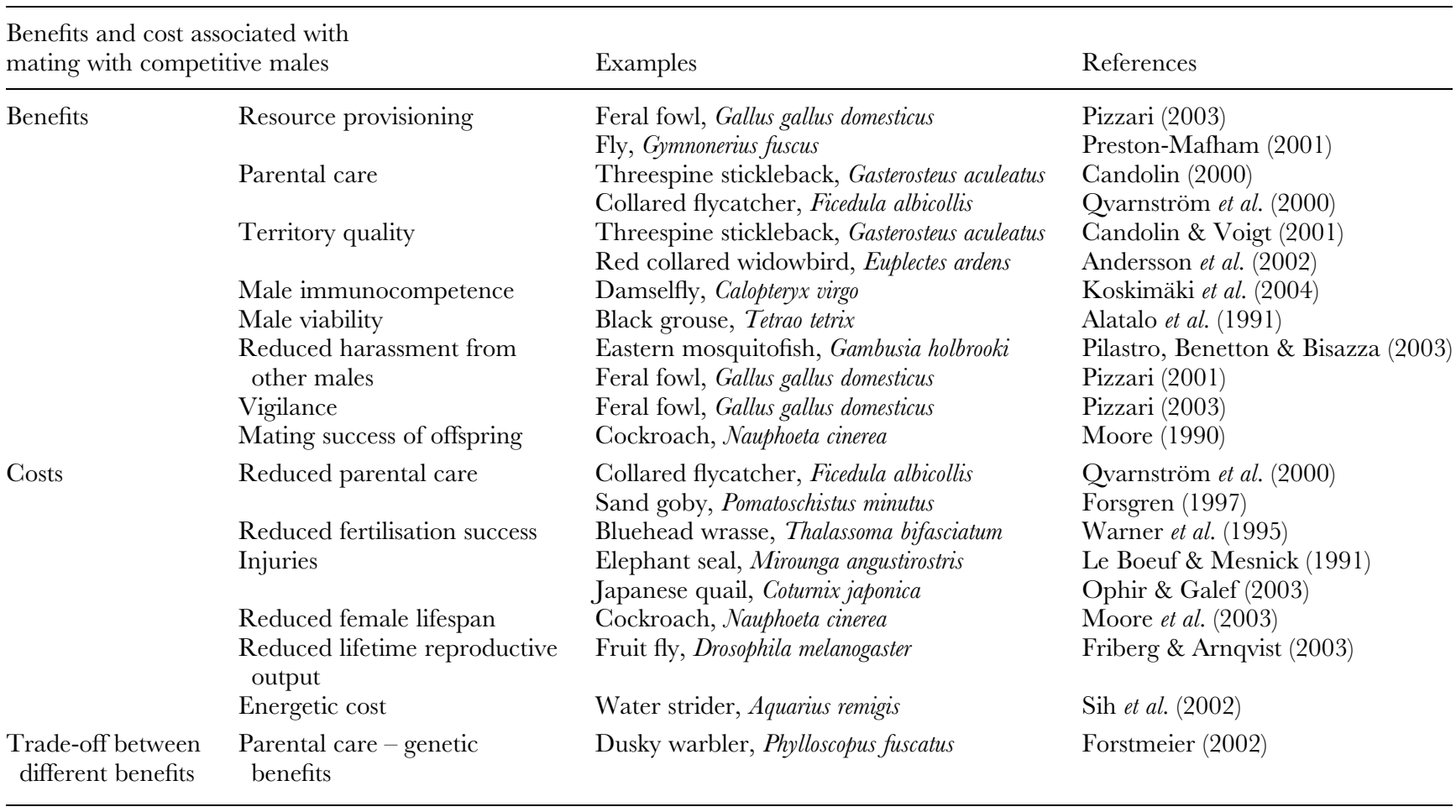

aculeatus, where males of high competitive ability establish larger territories with a more open structure than subdominant males. Dominant males consequently have a higher mate encounter rate than males with smaller and more vegetated territories, who suffer from lower visibility to females (Candolin \& Voigt, 2001). Further evidence for an effect of territory location on mating has been documented for the European blackbird, Turdus merula, where males compete for territories that overlap with females or for habitats likely to be occupied by females. The outcome of this intra-sexual competition then constrains subsequent mate choice (Creighton, 2001).

In these examples, whether competition facilitates or hampers female choice will likely depend on whether competition increases or decreases encounter rates with males offering benefits that increase the fitness of females (Table 2). It is conceivable that females, in these situations, could be denied the opportunity to encounter the best males unless these same males are also competitive enough to own their own (or the best) territories. In red-collared widowbirds (Andersson et al., 2002), for example, 'attractive' males with longer tails may be excluded from owning a territory which is critical to females for the purpose of nesting. Similarly in Lake Victorian cichlids, Pundamilia sp., red-coloured phenotypes are at an advantage over blue-coloured males during contests over territories required by females for breeding (Dijkstra, Seehausen \& Groothuis, in press) and this could affect female mate preferences which are based on male nuptial colouration (Seehausen \& Van Alphen, 1998; Seehausen \& Schluter, 2004).
Competition among territorial males may not only influence the number of females that detect a particular male, but also the ability of the male to detect females. For example, in the dragonfly, Perithemis tenera, the presence of neighbours increases the number of intrusions by other males on the territory and this disturbance reduces the detection of females (Eason \& Switzert, 2004). Whether this selective reduction in the number of males that detect and approach a female is beneficial or not to the female depends on the cost of harassment and whether it is high- or lowquality males that are mostly disturbed.

\section{(2) Acoustic mate detection}

Competition among males also could influence acoustic mate detection through interference during calling. Female frogs of some species prefer non-overlapping signals (Schwartz \& Wells, 1983, 1984; Wells \& Schwartz, 1984), probably because overlap may obscure fine temporal components of the call (Schwartz, 1987). Studies on some species have shown that neighbouring males can avoid overlap through call alternation (Wells, 1988). However, even under these circumstances, background noise from other individuals calling in the chorus could affect female choice. The effects of chorus noise on call detection have been studied in several species of hylid frog (Gerhardt \& Klump, 1988; Wollerman, 1999). These studies suggest that background noise could hamper a female's ability to choose between mates because females can detect only the nearest males and may be forced to incur increased search costs in 
order to sample more males by having to move around the chorus.

Another factor that could influence female detection of mates is the precedence effect often shown to occur where a male with a leading signal enjoys a mating advantage over his competitors whose signals are closely synchronised but temporally separated after the leader (Whitney \& Krebs, 1975; Dyson \& Passmore, 1988; Klump \& Gerhardt, 1992).

This is more often documented in acoustically signalling species but may also occur in animals that engage in visual group displays such as the synchronised waving of claws by male fiddler crabs, Uca annulipes (Backwell et al., 1998). Mating skews in favour of individuals that produce leading signals may not be due to the attractiveness of components of the leader's call per se. In acoustically communicating species, for instance, it may simply be a response to the sudden onset of sound or the leading signal may neurally inhibit components of the signal produced by other males (Greenfield, 1994). In this way, female attraction to the leading signal per se could override otherwise important cues contained within the temporal and spectral properties of the signal that may provide information regarding the attractiveness of a prospective mate (Greenfield, 1994).

\section{(3) Odour cues}

Competition can also play an important role in mate detection in species that rely on odour cues. In several species, females have been shown to use chemical cues to assess potential suitors (Potts, Manning \& Wakeland, 1991; Drickamer, 1992; Penn \& Potts, 1998). One way that competition can affect mate detection is the phenomenon of counter-marking, especially where the odour cues of one male are deposited directly over the mark of another. Such behaviours suggest a motivation to mask the bottom scent. Males that counter-mark an opponent's scent could, conceivably, enjoy a mating advantage as a consequence. In the pygmy loris, Nycticebus pygmaeus, males mark their territory boundaries with urine and engage in counter-marking. Females, in turn, appear to rely heavily on the olfactory modality to assess mates. In dichotomous choice tests, Fisher, Swaisgood \& Fitch-Snyder (2003) showed that female preferences in lorises were biased in favour of the countermarking male.

So far, we have shown that mate detection, a process that may occur via a range of sensory modalities, can be influenced by the competitive antics of rival males. The role of competition, however, does not end with the detection of potential suitors. Next we consider how competition impacts the process of mate evaluation.

\section{ROLE OF GOMPETITION ON MATE EVALUATION}

\section{(1) Females as instigators of competition}

Some of the most compelling evidence cited in support of females deriving benefits through male competition come from examples where females allegedly promote or encourage agonistic encounters between males (e.g. Cox \& Le Boeuf, 1977; Oda \& Masataka, 1995; Berglund \& Rosenqvist, 2001). When male sexual behaviours are deliberately manipulated, females are apparently able to influence the likelihood of being inseminated by certain males over others and thereby use competition to facilitate 'indirect' mate choice (Wiley \& Poston, 1996). For example, in several species of bird, females produce loud copulation calls that are believed to function as a form of fertility advertisement designed to promote competition among rival males for access to the calling female (Montgomerie \& Thornhill, 1989). Female fish also incite competition when they advertise their fertility through visual cues (Farr \& Travis, 1986; Bisazza, Marconato \& Marin, 1989). By promoting competition between prospective suitors, it is argued that females benefit indirectly by increasing their chances of mating with the winner of the contest (Thornhill, 1988; Montgomerie \& Thornhill, 1989, Semple, 1998). As reported in jungle fowl, Gallus gallus domesticus (Pizzari, 2001), and elephant seals, Mirounga angustirostris (Cox \& Le Boeuf, 1977), calls, when given, may also allow females to attract socially dominant males in order to disrupt any unsolicited copulatory advances made by unattractive subordinates.

In some species, females may have to trade off the benefits that might come from inciting competition against the very real risk of being injured as a result of any ensuing, escalated fights between competitors (Table 2). For example, Le Boeuf \& Mesnick (1991) reported that female northern elephant seals may incur lethal injuries as a result of fighting by males. Caution should also be exercised before generalising about the role of copulation calls in promoting male contests. Other possibilities for the utterance of these calls should be considered before any firm conclusions are drawn. In baboons, Papio cynocephalus ursinus, for example, copulation calls may allow females to mate with dominant males for the purpose of creating paternity uncertainty, thereby reducing the risk of male-induced infanticide (O'Connell \& Cowlishaw, 1994).

\section{(2) Competition and signal honesty}

In cases where the benefits females seek are correlated with dominance, competition may facilitate choice by ensuring signal honesty. For signals to reflect accurately the desired fitness gains to females, theory suggests that they must be costly to produce or maintain so that low-quality males cannot express as exaggerated signals as high-quality males (Zahavi, 1975, 1977, 1987). Recent theoretical models, however, demonstrate that certain benefits are not always signalled reliably (Kokko, 1998) and that some degree of dishonesty is allowed in an evolutionarily stable signalling system (Johnstone \& Grafen, 1993; Kokko, 1997; Viljugrein, 1997). Specifically, dishonest signalling may occur if signallers differ in their signalling strategies because of variation in the costs and benefits of signalling (Johnstone \& Grafen, 1993), or if the expression of the trait is subject to a life-history trade-off between present and future signalling effort (Kokko, 1997). In many species, however, the same trait used to attract mates also serves as a signal of fighting ability. Male-male competition could then 
operate as an additional factor to ensure honest signalling of condition since faking quality in a competitive setting could potentially be quite costly if condition is subsequently put to the test in a fight (Berglund et al., 1996).

For the choosing sex, the value of having prospective mates tested through competition may be especially pertinent in circumstances where individuals are making lifehistory trade-offs between present and future signalling effort. An example of such a trade-off occurs when males in poor physical condition elevate their signalling effort as a 'terminal effort' in order to maximise current reproductive opportunities when the prospects of future survival are grim (Kokko, 1997; Polak \& Starmer, 1998; Candolin, $1999 b$ ). Under this scenario, competition can actually facilitate female choice by ensuring that traits which simultaneously reflect dominance and fitness gains to females are signalled honestly as in sticklebacks (Candolin, 2000). On the other hand, if fighting ability does not reflect the benefits females seek, competition could actually promote dishonest signal expression with dominant males preventing subordinates from communicating accurately to females as in the interference of courtship displays reported by Howard, Moorman \& Whiteman (1997) in tiger salamanders, Ambystoma tigrinum tigrinum (see Section IV.4).

\section{(3) The value of eavesdropping}

Competition can be conspicuous and the public dissemination of information from a fight could be useful for choosy females. We earlier discussed circumstances of 'indirect' (Wiley \& Poston, 1996) mate choice where females may deliberately promote competition to increase their chances of mating with certain males. In cases of direct mate choice, females may also be able to 'eavesdrop' on aggressive encounters to gain information about potential suitors (McGregor \& Peake, 2000; Valone \& Templeton, 2002). Female fighting fish, Betta splendens, that 'eavesdrop' on the aggressive interactions between a pair of males subsequently spent more time near the winner, consistent with the idea that females were using information gathered from male-male displays to choose their mates (Doutrelant \& McGregor, 2000). A similar result was reported for male mate choice in sex-role-reversed pipefish, Syngnathus typhle (Berglund \& Rosenqvist, 2001). In pipefish, the 'B'-shaped body markings used to signal dominance among competing females also function as a signal of attraction (Berglund \& Rosenqvist, 2001). The signals themselves are not fixed and, instead, can be adjusted rapidly to changes in the environment. Berglund \& Rosenqvist (2001) reported that choosy male pipefish that witnessed female-female competition relied on markings displayed during contests to choose their mates over potentially more attractive displays conveyed in the absence of competition. Female Japanese quail, Coturnix japonica, also benefit from eavesdropping on aggressive interactions between potential mates (Ophir \& Galef, 2003). In that case, however, bearing witness to competition actually induces a preference for losers. By choosing the less dominant male, female quail forego direct and indirect benefits that accrue from pairing with winners of competition. However, they also avoid injury as males that are successful in competition are also more aggressive in courtship (Ophir \& Galef, 2003).

Females, however, may not necessarily gain any useful information from witnessing competition. In the Pacific blue-eye fish, Pseudomugil signifer, Wong (2004b) showed that being privy to competition did not induce a preference for either winners or losers. In blue-eye fish, females prefer males that engage in longer courtship, a trait unrelated to fighting ability.

\section{(4) Courtship interference}

One way that dominant males may hamper female assessment of prospective mates is through courtship interference. In sticklebacks, dominant males enjoyed a mating advantage when a female and two males were allowed to interact freely in an aquarium (Östlund-Nilsson \& Nilsson, 2000). However, no such advantage was found when the males were leashed to prevent physical contact. The difference in results was attributed to direct interference in trials where males were not tethered so that dominant individuals could prevent females from interacting with subordinates. Direct interference of courtship also has been reported in several species of salamandrids. Female tiger salamanders prefer males with long tails, a trait that confers no competitive advantage during male fights (Howard et al., 1997). Large body size is, however, important in agonistic encounters and larger, competitively superior males hamper female choice by interrupting the courtship of preferred long-tailed suitors. Similarly, male sword-tailed newts, Cynops ensicauda popei, interfere by shoving aside their courting competitors (Sparreboom, 1997).

Competitive disruption of another male's display can be subtle. Male guppies do not exhibit overt aggression or establish dominance hierarchies (Houde, 1997) but males jockey for position in an attempt to court receptive females. In this way, behaviourally dominant but unattractive individuals can restrict the mating opportunities of more attractive rivals by interfering with the female's ability to assess potential suitors accurately (Kodric-Brown, 1992).

The spatial distribution of males appears to be important in some species. Male-male interactions could have more of an impact on female choice in areas where territories are dense. Male sand gobies are capable of disrupting the courtship of rivals, making it more difficult for females to choose between prospective mates (Kangas \& Lindström, 2001). Paternal competence in sand gobies appears to be communicated through courtship and females prefer good fathers over dominant males (Forsgren, 1997). Hence, there is potential for competition to hamper female choice. Nest density, however, is likely to determine the extent to which competition will affect female choice. The distribution of nests in the field shows a great deal of spatial variation. In some cases, females must move a considerable distance between males. When nests are sparse, mate assessment is unlikely to be fettered since females can view each male independently as well as move back and forth between potential suitors. However, when densities are high, a female may encounter situations where several males try to court 
her simultaneously. Although this scenario may allow females to compare different males more directly female assessment of potential suitors could also be made more difficult due to competitive interference. In lekking species, the frequency of courtship disruption can be high (e.g. $68 \%$, Trail, 1985). For example, in the cock of the rock, Rupicola rupicola, and the buff-breasted sandpiper, Tryngites subruficollis, females are often driven away as a result of continual harassment or prevented from mating with the preferred male at the lek (Trail, 1985; Lanctot et al., 1998).

Interference of display signals by competing males also may be a frequent occurrence in acoustically communicating animals. Periodical cicadas, Magicicada spp., form dense mating aggregations where males compete intensely for limited mating opportunities due to a dramatically maleskewed operational sex ratio. A female responds favourably to a potential suitor's acoustic repertoire by flicking her wings in a timed response to the courting male. Cooley \& Marshall (2001) showed that males use carefully timed 'buzz' signals to usurp the courtship of their rivals and to obscure the calls of potential interlopers.

Although competition may affect a male's ability to signal accurately to females, in some species, females may rely on multiple cues to identify the most suitable mates. In northern pintails, Anas acuta, for example, dominant drakes are able to disrupt the courtship of subordinates (Sorenson \& Derrickson, 1994). Females, however, are able to use other choice cues to select their mates. The advantage of using multiple cues is that the relative importance ascribed to each cue can be varied depending on context in order to select the best males as shown, for example, in guppies (Kodric-Brown, 1993) and yellow browed leaf warblers, Phylloscopus inornatus (Marchetti, 1998).

\section{ROLE OF GOMPETITION IN DICTATING MATING OUTCOMES}

As alluded to at the beginning of this paper, mating success often is skewed in favour of socially dominant males. However, is this mating skew the result of female choice selecting for 'attractive' males or male competition successfully excluding other males and preventing females from realising their actual preferences? We have already seen that competition can have important consequences in either facilitating or hindering the accurate assessment of mates. Evidence also suggests that competition could be important in dictating mating outcomes. Males may, for instance, guard females and, in so doing, prevent them from mating multiply to enhance genetic diversity of offspring as in Sika deer, Cerous nippon (Endo \& Doi, 2002). In some cases, competition can reinforce preference for dominant individuals or traits that are positively correlated with dominance. For example, in Japanese medaka, Oryzias latipes, both male-male competition and female choice result in a mating advantage for larger males (Howard et al., 1998). However, the two processes differed in their relative contribution to the observed pattern of mating success. Specifically, when males were allowed to interact, the effect of competition meant that large dominant males obtained an even greater number of matings compared to those received when mate choice was acting alone. Similarly, in rock shrimp, Rhynchocinetes typhus, receptive females first 'seized' by subdominant males are taken over in rapid succession by more dominant (and attractive) males (Thiel \& Correa, 2004).

Under some situations, however, females may not be able to realise their preferences even if socially dominant males are preferred. This is seen, for example, in reindeer, Rangifer tarandus. Female reindeer prefer high-ranking, socially dominant stags and the mating skew in favour of such males is reinforced early in the breeding season when dominant stags are able to sequester females from subordinates (Hirotani, 1994). However, less attractive lower ranking males are able to secure more matings late in the season when high-ranking males become physically exhausted from their mating efforts (Hirotani, 1994). Similarly, in dungflies, Scatophaga stercoraria, female preference for dominant males is realised only when densities at the cow pat are low (Borgia, 1981). When densities are high, socially dominant males may not be able to exclude other males from 'capturing' females. A similar situation is also observed in species of colonial blackbirds where the extent to which a few males are able to monopolise access to females is related to colony size (Webster \& Robinson, 1999).

\section{(1) Capitalizing on error-prone choice}

In some cases, mate choice can be prone to error. Males, in turn, might be able to capitalize on this error and, in so doing, dictate mating outcomes. Specifically, subdominant males could, potentially, parasitize the attractiveness of more dominant suitors. This is seen, for example, in the cooperatively breeding superb fairy-wren, Malurus cyaneus. In this species, subdominant males help with the provisioning of young and are able to achieve both within-group and extra-group mating success (Mulder et al., 1994). Double \& Cockburn (2003) recently demonstrated that the extragroup reproductive success of subordinates was greatly influenced by the attractiveness of dominant males. Specifically, subordinate males helping on territories with early-moulting (i.e. attractive) dominant males were, themselves, more likely to sire extra-group offspring. An analogous situation is also seen in many lek-forming species, such as marine iguanas, Amblyrhynchus cristatus (Wikelski, Carbone \& Trillmich, 1996), where less attractive males are able to increase their own mating success by clustering and/ or displaying with more attractive suitors ('hotshot' model of lek formation; sensu Beehler \& Foster, 1988).

\section{(2) Alternative strategies}

Competition also could lead to alternative male mating strategies that by-pass female choice. This is seen, for example, in scorpionflies, Panorpa penicillata. Male scorpionflies generally court females by offering them a nuptial gift in the form of a dead insect. Males that are excluded from access to dead insects through male competition become aggressive rapists (Thornhill, 1979, 1980). A less extreme 
form of alternative mating tactics which can impact female choice is found in the pygmy swordtail, Xiphophorus pygmaeus, a species which exhibits a male colour polymorphism. Female swordtails prefer blue males but gold males are dominant during agonistic encounters and are more aggressive in pursuing females (Kingston, Rosenthal \& Ryan, 2003). In the quacking frog, Crinia georgiana, males allocate less time to calling to attract females at higher densities (Byrne \& Roberts, 2004). Males, instead, spend more time as non-moving satellites or roamers, 'seizing' females opportunistically. In the case of blue gill sunfish, Lepomis macrochirus, sneakers not only steal fertilisations from parental males but the effect can be a reduction in the amount of care that the cuckolded parental male subsequently invests in the female's offspring (Neff, 2003).

\section{(3) Overriding choice}

In situations where females do not prefer dominant males (or traits correlated with dominance), competition could directly override female preference so that competitively superior males end up enjoying a mating advantage over preferred suitors. For instance, dominant male trout, Salmo trutta, which are aggressive to females during spawning, enjoy a mating advantage by excluding competitors and are able to override female preference for males with a larger adipose fin (Petersson et al., 1999). A comparable situation may also occur in water striders, Aquarius remigis (Sih et al., 2002). Male water striders hitchhike on the backs of females during copulation. Females incur an energetic cost from carrying the male on their backs, which increases with male body size. Further, females are constantly harassed by males. Smaller males, therefore, represent a 'lesser evil' in this system of sexual conflict where females are constantly trying to resist the amorous attention of males. It is not yet known whether females actually prefer smaller males but such a preference is likely since smaller males are a less costly alternative to larger ones: the former are lighter to carry and could be used as a less energetically costly shield against other males. Larger males, however, are at a competitive advantage and are better able to overcome the resistance of females.

Male competition, however, does not always override female preferences. Female great snipe, Gallinago media, visiting the territory of a prospective mate often are disrupted by neighbouring males on the lek (Sæthers, Fiske \& Kålås, 1999). However, females appear not to be easily dissuaded by the harassment and were much more likely to return and mate with the male from which they were initially chased away instead of mating with the disrupter or other males. This finding suggests that female great snipes are choosy despite harassment and thus competition does not necessarily hamper a female's ability to mate with preferred suitors. Similar observations also have been reported in other taxa including sand gobies (Kangas \& Lindström, 2001), pheasants Phasianus colchicus (Göransson et al., 1990), crickets Gryllus bimaculatus (Simmons, 1991) and topi antelopes Damaliscus lunatus (Bro-Jorgensen, 2003).

The importance of competitive ability may also differ depending on whether a female is choosing a social mate or a genetic father for her offspring. For example, in the dusky warbler, Phylloscopus fuscatus, males compete for territories of different qualities and females prefer high-quality territories when choosing a social mate. However, analysis of extra-pair paternity shows that females do not prefer to copulate with males most successful in competition over territories (Forstmeier, 2002). Similarly, in superb fairywrens, dominant males that provide a considerable level of paternal care may still have most of their young sired by extra-group males (Mulder et al., 1994; Double \& Cockburn, 2000).

\section{DIREGTIONS FOR FUTURE STUDIES}

We have identified, through examples, circumstances where competition can have beneficial, as well as detrimental, effects on female choice (Table 2). Researchers are only now beginning to tackle the question of whether females should prefer mating with competitive males. This trend should be encouraged because it goes to the heart of how the two key components of sexual selection might interact. Here it is important to consider both the costs, as well as the benefits, of females mating with males based on competitive ability. In particular, several studies have recently underscored the need to give greater thought to the indirect genetic benefits of mating with particular males over others (reviewed in Kokko et al., 2003). Even if a female suffers a direct cost, it is still possible that the genetic benefits could make up for the detriments that may be incurred. Sexual conflict is currently one of the hottest topics in evolutionary ecology and although the burgeoning focus on sexual discord has, thus far, been illuminating, there has also been an unfortunate tendency to view males as 'winners' and females as 'losers' in the evolutionary game. Such designations can be misleading since, in any population with equal sex ratios, males and females have equal fitness on average and only individual fitness can vary (Getty, 1999; Arnqvist, 2004). In any case, researchers are likely to be rewarded by directing greater effort towards investigating the net benefit to females, and to move beyond the assumption that females are suffering and 'losing' solely because competition influences which males they end up mating with or with how many males they mate.

Researchers may also like to examine more closely how interactions between male competition and female choice might drive the evolution of male traits. Traditionally, the two main forces of sexual selection have been assumed to act in unison and select for elaboration of the same traits. New work, however, suggests that male competition and female choice can also work in opposing directions (Moore \& Moore, 1999; Bonduriansky \& Rowe, 2003; Candolin, 2004) or even select for different traits (Andersson et al., 2002). The evolutionary consequences of potential conflict between the two main processes of sexual selection could be illuminating and provide insights into some of evolutionary biology's most intriguing topics, from the maintenance of additive genetic variation (Moore \& Moore, 1999) and the evolution of multiple ornaments (e.g. Andersson 
et al., 2002; Candolin, 2005), to population differentiation and the process of speciation (Magurran, 1998; Seehausen \& Schluter, 2004; van Doorn, Diekmann \& Weissing, 2004).

The majority of sexual selection studies have tended to consider male sexual displays free from the constraints of life-history. Injecting a life-history perspective into sexual selection studies is likely to benefit our understanding of how male competition impacts female choice. Recent models have, for instance, shown that the optimal allocation of resources by males into current sexual advertisement can be closely linked to an individual's future reproduction and survival (Kokko, 1998). Resources invested into mate attraction must also occur in competition with other components of male fitness, such as time and energy spent interacting with rivals, and/or effort devoted to parental care (Qvarnström, 1997; Griffith \& Sheldon, 2001). Moreover, as discussed earlier, male-male competition can cause male signalling effort to vary within individuals. This, in turn, can have consequences for the honesty of advertisement displays and, therefore, influence whether female choice is helped or hindered by competitive interactions. Understanding plasticity in the expression of sexually-selected traits is important because, like variation between individuals, it too can influence the power of selection (Griffith \& Sheldon, 2001). In this regard, a suite of recent conceptual and theoretical contributions in the sexual selection literature should provide a useful springboard for future research (Kokko, 1997, 1998; Höglund \& Sheldon, 1998; Magrath \& Komdeur, 2003).

This review has focused largely on how male competition might impact female fitness. It is important, however, to realize that female choice can also have equally significant consequences for male competition and male fitness. The fitness of dominant males increases when competition and mate choice act in unison and are mutually reinforcing, but decreases when the two processes are opposing. However, taking a population-wide view, female choice could have a potentially negative effect on average male fitness if choice induces costly competition that results in the loss of energy and time or increases injuries. On the other hand, female choice can also have a positive effect on the fitness of the population if, for example, it increases the genetic quality of the population. The interplay between the two processes of sexual selection and the consequences this may have for individual and population-wide fitness is an interesting subject that will provide a fruitful area for future research.

\section{GONGLUSIONS}

(1) Male competition and female mate choice have each received considerable research attention but a unified understanding of how they interact has, hitherto, proven elusive. This may be compounded, in part, by largely polarised opinions on whether competition should have beneficial or detrimental effects on female choice.
(2) Competition can, in reality, both help and hinder the choice process, and depends on whether it allows females to realise high breeding value for total fitness. Specifically, if competition enables females to maximise their fitness, then the mate choice process is assisted.

(3) There are three important stages when competition can have an effect on precopulatory mate choice: during mate detection, during mate evaluation, and in dictating actual mating outcomes.

(4) Competition can affect female detection of mates by influencing which males establish territories, when and where these territories are established, and/or the size of the territories. Competition can also affect the ability of females to sample between prospective mates, and the males ability to detect females.

(5) Competition can have profound effects on mate evaluation. In some taxa, females have even been known to instigate competition to ensure mating with particular males and/or eavesdrop on aggressive interactions to help them choose between prospective suitors.

(6) Competition can impact the honesty of signals relied upon by females to assess prospective suitors. In cases where fitness gains to females are correlated with competitive ability, this can ensure the honest expression of signals. However, where fitness gains are uncorrelated with male competitive prowess, competition could lead to dishonest signal expression with subdominant, but 'attractive' males being prevented from signalling their quality accurately to females.

(7) Courtship interference is one way in which male competition might hamper female assessment of mates. Interference can be overt or it can be subtle. In any case, the spatial distribution of males is likely to be influential with greater disruption possible when territories are dense. Females, however, may not always be adversely affected and could rely on multiple cues to choose mates even in a setting wrought by competitive interference.

(8) Competition could be important in dictating mating outcomes. In some cases this can reinforce preference. In other situations, however, male competition may override female preferences by preventing them from mating with preferred suitors.

(9) A better understanding of the interactions between male competition and female mate choice is likely to provide insights into some of evolutionary ecology's most intriguing questions including the evolutionary potential of sexual selection, the elaboration of male traits, the maintenance of additive genetic variation and the speciation process.

\section{AGKNOWLEDGEMENTS}

We thank Patricia Backwell, Jessica Buckingham, Andrew Cockburn, Peter Dijkstra, Heidi Fisher, Michael Jennions, Scott Keogh, Robert Magrath, Andrea Manica, Elizabeth Neeley, Gil Rosenthal, and Carley Schacter for their comments and insights. This study was supported by an Australian Postgraduate Award, a Sir Keith Murdoch Fellowship, and a Centre for International Mobility Fellowship (to B.B.M.W) and the Academy of Finland (to U.C.). 


\section{REFERENGES}

Alatalo, R. V., Höglund, J. \& Lundberg, A. (1991). Lekking in the black grouse - a test of male viability. Nature 352, 155-156.

Andersson, S., Pryke, S. R., Örnborg, J., Lawes, M.J. \& ANDERsson, M. (2002). Multiple receivers, multiple ornaments, and a trade-off between agonistic and epigamic signaling in a widowbird. American Naturalist 160, 683-691.

ARngvist, A. (2004). Sexual conflict and sexual selection: lost in the chase. Evolution 58, 1383-1388.

Backwell, P. R. Y., Jennions, M. D., Passmore, N. I. \& Christy, J. H. (1998). Synchronous waving in a fiddler crab. Nature 391, 31-32.

Badyaev, A. V. \& Duckworth, R. A. (2003). Context-dependent sexual advertisement: plasticity in development of sexual ornamentation throughout the lifetime of a passerine bird. Fournal of Evolutionary Biology 16, 1065-1076.

Badyaev, A. V. \& Hill, G. E. (2002). Paternal care as a conditional strategy: distinct reproductive tactics associated with elaboration of plumage ornamentation in the house finch. Behavioral Ecology 13, 591-597.

Beehler, B. M. \& Foster, M. S. (1988). Hotshots, hotspots, and female preference in the organization of lek mating systems. American Naturalist 131, 203-219.

Berglund, A., Bisazza, A. \& Pilastro, A. (1996). Armaments and ornaments: an evolutionary explanation of traits of dual utility. Biological Journal of the Linnean Society 58, 385-399.

Berglund, A. \& Rosenqvist, G. (2001). Male pipefish prefer dominant over attractive females. Behavioral Ecology 12, 402-406.

BIRKHEAD, T. R. (1998). Sperm competition in birds: mechanisms and function. In Sperm Competition and Sexual Selection (eds. T. R. Birkhead and A. P. Moller), pp. 578-622. Academic Press, London.

Bisazza, A., Marconato, A. \& Marin, G. (1989). Male competition and female choice in Padogobius martensi (Pisces, Gobiidae). Animal Behaviour 38, 406-413.

BorgiA, G. (1981). Mate selection in the fly Scatophaga stercoraria: female choice in a male-controlled system. Animal Behaviour 29, 71-80.

Bonduriansky, R. \& Rowe, L. (2003). Interactions among mechanisms of sexual selection on male body size and head shape in a sexually dimorphic fly. Evolution 57, 2046-2053.

Bro-Jorgensen, J. (2003). No peace for estrous topi cows on leks. Behavioral Ecology 14, 521-525.

Brooks, R. (2000). Negative genetic correlation between male sexual attractiveness and survival. Nature 406, 67-70.

Byrne, P. G. \& Roberts, J. D. (2000). Does multiple paternity improve fitness of the frog Crinia georgiana? Evolution 54, 968-973.

Byrne, P. G. \& Roberts, J. D. (2004). Intrasexual selection and group spawning in quacking frogs (Crinia georgiana). Behavioral Ecology 15, 872-882.

Candolin, U. (1999a). Male-male competition facilitates female choice in sticklebacks. Proceedings of the Royal Society of London B 266, 785-789.

Candolin, U. (1999b). The relationship between signal quality and physical condition: is sexual signalling honest in the three-spined stickleback. Animal Behaviour 58, 1261-1267.

CAndolin, U. (2000). Increased signalling effort when survival prospects decrease: male-male competition ensures honesty. Animal Behaviour 60, 417-422.
Candolin, U. (2004). Opposing selection on a sexually dimorphic trait through female choice and male competition in a water boatman. Evolution 58, 1861-1864.

Candolin, U. (2005). Why do multiple traits determine mating success? Differential use in female choice and male competition in a water boatman. Proceedings of the Royal Society of London B 272, 47-52.

Candolin, U. \& Voigt, H. R. (2001). Correlation between male size and territory quality: consequence of male competition or predation risk? Oikos 95, 225-230.

Chapman, T., Liddle, L. F., Kalb, J. M., Wolfner, M. F. \& Partridge, L. (1995). Cost of mating in Drosophila melanogaster females is mediated by male accessory gland products. Nature 373, 241-244.

Chippindale, A. K., Gibson, J. R. \& Rice, W. R. (2001). Negative genetic correlation for adult fitness between sexes reveals ontogenetic conflict in Drosophila. Proceedings of the National Academy of Sciences of the United States of America 98, 1671-1675.

Civetta, A. \& Clink, A. G. (2000). Correlated effects of sperm competition and postmating female mortality. Proceeding of National Academy of Sciences of the United States of America 97, 13162-13165.

Cooley, J. R. \& Marshall, D. C. (2001). Sexual signaling in periodical cicadas, Magicicada spp. (Hemiptera: Cicadidae). Behaviour 138, 827-855.

Cordero, G. \& Eberhard, W. G. (2003). Female choice of sexually antagonistic male adaptations: a critical review of some current research. Fournal of Evolutionary Biology 16, 1-6.

Cox, C. R. \& Le Boeuf, B.J. (1977). Female incitation of male competition: a mechanism in sexual selection. American Naturalist 111, 317-335.

Creighton, E. (2001). Mate acquisition in the European blackbird and its implications for sexual strategies. Ethology Ecology and Evolution 13, 247-260.

Dijkstra, P. D., Seehausen, O. \& Groothuis, T. G. G. (in press). Direct male-male competition can facilitate invasion of new colour types in Lake Victorian cichlids. Behavioral Ecology and Sociobiology.

Double, M. \& Cockburn, A. (2000). Pre-dawn infidelity: females control extra-pair mating in superb fairy-wrens. Proceedings of the Royal Society of London B 267, 465-470.

Double, M. \& Cockburn, A. (2003). Subordinate superb fairywrens (Malurus cyaneus) parasitize the reproductive success of attractive dominant males. Proceedings of the Royal Society of London B 270, 379-384.

Doutrelant, C. \& MaGregor, P. K. (2000). Eavesdropping and mate choice in female fighting fish. Behaviour 137, 1655-1669.

Drickamer, L. C. (1992). Oestrus female mice discriminate dominant from subordinate males and sons of dominant and sons of subordinate males by odour cues. Animal Behaviour 43, 868-870.

Duckworth, R. A., MendonçA, M. T. \& Hill, G. E. (2004). Condition-dependent sexual traits and social dominance in the house finch. Behavioral Ecology 15, 779-784.

Dyson, M. L. \& Passmore, N. I. (1988). Two-choice phonotaxis in Hyperolius marmoratus (Anura: Hyperoliidae); the effect of temporal variation in presented stimuli. Animal Behaviour 36, 648-652.

Eason, P. K. \& Switzert, P. V. (2004). The costs of neighbors for a territorial dragonfly, Perithemis tenera. Ethology 110, 37-47.

Endo, A. \& DoI, T. (2002). Multiple copulations and postcopulatory guarding in a free-living population of Sika deer (Cervus nippon). Ethology 108, 739-747. 
EngQvist, L. \& Sauer, K. P. (2002). A life-history perspective on strategic mating effort in male scorpionflies. Behavioral Ecology 13, 632-636.

FArR, J. A. \& Travis, J. (1986). Fertility advertisement by female sailfin mollies, Poecilia latipinna (Pisces: Poeciliidae). Copeia 1986, 467-472.

Fisher, H. S., Swaisgood, R. R. \& Fitch-Snyder, H. (2003). Countermarking by male pygmy lorises (Nycticebus pygmaeus): do females use odor cues to select mates with high competitive ability? Behavioral Ecology and Sociobiology 53, 123-130.

ForsGren, E. (1997). Female sand gobies prefer good fathers over dominant males. Proceedings of the Royal Society of London B 264, 1283-1286.

Forstmeier, W. (2002). Factors contributing to male success in the polygynous warbler (Phylloscopus fuscatus). Behaviour 139, 1361-1381.

Forstmeier, W., Kempenaers, B., Meyer, A. \& Leisler, B. (2002). A novel song parameter correlates with extra-pair paternity and reflects male longevity. Proceedings Of the Royal Society of London B 269, 1479-1485.

Friberg, U. \& Arnqvist, G. (2003). Fitness effects of female mate choice: preferred males are detrimental for Drosophila melanogaster females. Fournal of Evolutionary Biology 16, 797-811.

Galvani, A. \& Johnstone, R. A. (1998). Sperm allocation in an uncertain world. Behavioral Ecology and Sociobiology 44, 161-168.

Gerhardt, H. C. \& Klump, G. M. (1988). Masking of acoustic signals by the chorus background noise in the green tree frog: a limitation on mate choice. Animal Behaviour 36, 1247-1249.

GetTy, T. (1999). Chase-away sexual selection as noisy reliable signaling. Evolution 53, 299-302.

Göransson, G., Von Schantz, T., Fröberg, I., Helgée, A. \& Wittzell, H. (1990). Male characteristics, viability and harem size in the pheasant, Phasianus cochicus. Animal Behaviour 40, 89-104.

Greenfield, M. D. (1994). Cooperation and conflict in the evolution of signal interactions. Annual Review of Ecology and Systematics 25, 97-126.

Griffith, S. C. \& Sheldon, B. C. (2001). Phenotypic plasticity in the expression of sexually selected traits: neglected components of variation. Animal Behaviour 61, 987-993.

Griffith, S. C., Owens, I. P. F. \& Thuman, K. A. (2002). Extra pair paternity in birds: a review of interspecific variation and adaptive function. Molecular Ecology 11, 2195-2212.

Hegyi, G., Torok, J. \& Toth, L. (2002). Qualitative population divergence in proximate determination of a sexually selected trait in the collared flycatcher. Fournal of Evolutionary Biology 15, $710-719$

Hine, E., Lachish, S., Higgie, M. \& Blows, M. W. (2002). Positive genetic correlation between female preference and offspring fitness. Proceedings of the Royal Society of London B 269, 2215-2219.

Hirotani, A. (1994). Dominance rank, copulatory behaviour and estimated reproductive success in male reindeer. Animal Behaviour 48, 929-936.

Höglund, J. \& Sheldon, B. C. (1998). The cost of reproduction and sexual selection. Oikos 83, 478-483.

Holland, B. \& Rice, W. R. (1999). Experimental removal of sexual selection reverses intersexual antagonistic coevolution and removes a reproductive load. Proceedings of the National Academy of Sciences USA 96, 5083-5088.

Houde, A. E. (1997). Sex, Color, and Mate Choice in Guppies. Princeton University Press, Princeton.
Howard, R. D., Martens, R. S., Innis, S. A., Drnevich, J. M. \& HaLe, J. (1998). Mate choice and mate competition influence male body size in Japanese medaka. Animal Behaviour $\mathbf{5 5}$, $1151-1163$.

Howard, R. D., Moorman, R. S. \& Whiteman, H. H. (1997). Differential effects of mate competition and mate choice on eastern tiger salamanders. Animal Behaviour 53, 1345-1356.

Johnstone, R. A. \& Grafen, A. (1993). Dishonesty and the handicap principle. Animal Behaviour 46, 759-764.

Kangas, N. \& LindströM, K. (2001). Male interactions and female mate choice in the sand goby, Pomatoschistus minutus. Animal Behaviour 61, 425-430.

Kingston, J. J., Rosenthal, G. G. \& Ryan, M. J. (2003). The role of sexual election in maintaining a colour polymorphism in the pygmy swordtail, Xiphophorus pygmaeus. Animal Behaviour 65, 735-743.

Klump, G. M. \& Gerhardt, H. C. (1992). Mechanisms and function of call-timing in male-male interactions in frogs. In Playback and Studies of Animal Communication (ed. P. K. McGregor), pp. 153-174. Plenum Press, New York.

Kodric-Brown, A. (1992). Male dominance can enhance mating success in guppies. Animal Behaviour 44, 165-167.

Kodric-Brown, A. (1993). Female choice of multiple male criteria in guppies: interacting effects of dominance, coloration and courtship. Behavioural Ecology and Sociobiology 32, 415-420.

Kokкo, H. (1997). Evolutionarily stable strategies of agedependent sexual advertisement. Behavioral Ecology and Sociobiology 41, 99-107.

Kokko, H. (1998). Should advertising parental care be honest? Proceeding of the Royal Society of London B 265, 1871-1878.

Kokko, H., Brooks, R., Jennions, M. D. \& Morley, J. (2003). The evolution of mate choice and mating biases. Proceeding of the Royal Society of London B 270, 653-664.

Koskimäki, J., Rantala, M.J., Taskinen, J., Tynkkynen, K. \& Suhonen, J. (2004). Immunocompetence and resource holding potential in the damselfly, Calopteryx virgo L. Behavioral Ecology 15, 169-173.

Lanctot, R. B., Weatherhead, P. J., Kempenaers, B. \& Scribner, K. T. (1998). Male traits, mating tactics and reproductive success in the buff-breasted sandpiper, Tryngites subruficollis. Animal Behaviour 56, 419-432.

Le Boeuf, B. J. \& Mesnick, S. L. (1991). Sexual behaviour of male northern elephant seals. I. Lethal injuries to adult females. Behaviour 116, 142-162.

LindströM, K. (1992). The effect of resource holding potential, nest size and information about resource quality on the outcome of intruder-owner conflicts in the sand goby. Behavioral Ecology and Sociobiology 30, 53-58.

Magrath, M. J. L. \& Komdeur, J. (2003). Is male care compromised by additional mating opportunity? Trends in Ecology and Evolution 18, 424-430.

Magurran, A. E. (1998). Population differentiation without speciation. Philosophical Transactions of the Royal Society of London B 353, 275-286.

Marchetti, K. (1998). The evolution of multiple male traits in the yellow-browed leaf warbler. Animal Behaviour 55, 361-376.

McGregor, P. K. \& Peake, T. (2000). Communication networks: social environments for receiving and signaling behaviour. Acta Ethologica 2, 71-81.

Møller, A. P. \& Thornhill, R. (1998). Male parental care, differential parental investment by females and sexual selection. Animal Behaviour 55, 1507-1515. 
Montgomerie, R. \& Thornhill, R. (1989). Fertility advertisement in birds: a means of inciting male-male competition? Ethology 81, 209-220.

Moore, A. J. (1990). The inheritance of social dominance, mating behaviour and attractiveness to mates in Nauphoeta cinerea. Animal Behaviour 39, 388-397.

Moore, A. \& Moore, P. (1999). Balancing sexual selection through opposing mate choice and male competition. Proceeding of the Royal Society of London Series B 266, 711-716.

Moore, A.J., Gowaty, P. A., Wallin, W. G. \& Moore, P.J. (2001). Sexual conflict and the evolution of female mate choice and male social dominance. Proceeding of the Royal Society of London $B$ 268, 517-523.

Moore, A. J., Gowaty, P. A. \& Moore, P.J. (2003). Females avoid manipulative males and live longer. Fournal of Evolutionary Biology 16, 523-530.

Mü hlhäuser, C. \& Blankenhorn, W. U. (2002). The costs of avoiding matings in the dung fly Sepsis cynipsea. Behavioral Ecology and Sociobiology 13, 359-365.

Mulder, R. A., Dunn, P. O., Cockburn, A., Lazenby-Cohen, K. A. \& Howell, M.J. (1994). Helpers liberate female fairywrens from constraints on extra-pair mate choice. Proceeding of the Royal Society of London Series B 255, 223-229.

NefF, B. D. (2003). Decisions about parental care in response to perceived paternity. Nature 422, 716-719.

O’Connell, S. M. \& Cowlishaw, G. (1994). Infanticide avoidance, sperm competition and mate choice-the function of copulation calls in female baboons. Animal Behaviour 48, 687-694.

OdA, R. \& Masataka, N. (1995). Function of copulatory vocalizations in mate choice by females of japanese macaques (Macaca fuscata). Folia Primatologica 64, 132-139.

Ophir, A. G. \& Galef, B. G. (2003). Female japanese quail that 'eavesdrop' on fighting males prefer losers to winners. Animal Behaviour 66, 399-407.

Östlund-Nilsson, S. \& Nilsson, G. E. (2000). Free choice by female sticklebacks: lack of preference for male dominance traits. Canadian Fournal of Zoology 78, 1251-1258.

PAI, A. T. \& YAn, G. Y. (2002). Polyandry produces sexy sons at the cost of daughters in red flour beetles. Proceedings of the Royal Society of London B 269, 361-368.

Penn, D. \& Potts, W. K. (1998). Chemical signals and parasitemediated sexual selection. Trends in Ecology and Evolution 13, 391-396.

Petersson, E., Järvi, T., Olsén, H., Mayer, I. \& Hedenskog, M. (1999). Male-male competition and female choice in brown trout. Animal Behaviour 57, 777-783.

Pilastro, A., Benetton, S. \& Bisazza, A. (2003). Female aggregation and male competition reduce costs of sexual harrassment in the mosquitofish Gambusia holbrooki. Animal Behaviour 65, $1161-1167$.

PizZARI, T. (2001). Indirect partner choice through manipulation of male behaviour by female fowl, Gallus gallus domesticus. Proceeding of the Royal Society of London B 268, 181-186.

PizzARI, T. (2001). Food, vigilance and sperm: the role of male direct benefits in the evolution of female preference in a polygamous bird. Behavioral Ecology 14, 593-601.

Polak, M. \& Starmer, W. T. (1998). Parasite-induced risk of mortality elevates reproductive effort in male Drosophila. Proceeding of the Royal Society of London B 265, 2197-2201.

Potts, W. K., Manning, C. J. \& Wakeland, E. K. (1991). Mating patterns in seminatural populations influenced by MHC genotype. Nature 352, 619-621.
Preston-Mafham, K. (2001). Resource defence mating system in two flies from Sulawesi: Gymnonerius fuscus Wiedemann and Telostylinus sp near duplicatus Wiedemann (Diptera : Neriidae). Journal of Natural History 35, 149-156.

Pryke, S. R. \& Andersson, S. (2003a). Carotenoid-based epaulettes reveal male competitive ability: experiments with resident and floater red-shouldered widowbirds. Animal Behaviour 66, 217-224.

Pryke, S. R. \& Andersson, S. (2003b). Carotenoid-based status signalling in red-shouldered widowbirds (Euplectes axillaris): epaulet size and redness affect captive and territorial competition. Behavioral Ecology and Sociobiology 53, 393-401.

Qvarnström, A. (1997). Experimentally increased badge size increases male competition and reduces male parental care in the collared flycatcher. Proceedings of the Royal Society of London B 264, 1225-1231.

Qvarnström, A. (1999). Different reproductive tactics in male collared flycatchers signalled by size of secondary sexual character. Proceedings of the Royal Society of London B 266, 2089-2093

Qvarnström, A. \& Forsgren, E. (1998). Should females prefer dominant males? Trends in Ecology and Evolution 13, 498-501.

Qvarnström, A., Pärt, T. \& Sheldon, B. C. (2000). Adaptive plasticity in mate preference linked to differences in reproductive effort. Nature 405, 344-346.

Qvarnström, A., Griffith, S. G. \& Gustafsson, L. (2000). Male-male competition and parental care in collared flycatchers (Ficedula albicollis): an experiment controlling for differences in territory quality. Proceedings of the Royal Society of London B 267, $2547-2552$.

Reale, D., Bousses, P. \& Chapuis, J. L. (1996). Femalebiased mortality induced by male sexual harassment in a feral sheep population. Canadian Journal of Zoology 74, $1812-1818$.

SÆthers, S. A., Fiske, P. \& KÅlÅs, J. A. (1999). Pushy males and choosy females: courtship disruption and mate choice in the lekking great snipe. Proceeding of the Royal Society of London B 266, 1227-1234.

Schwartz, J.J. (1987). The function of call alternation in anuran amphibians: a test of three hypotheses. Evolution $\mathbf{4 1}$, $461-471$

Schwartz, J.J. \& Wells, K. D. (1983). The influence of background noise on the behaviour of a neotropical treefrog, Hyla ebraccata. Herpetologica 39, 121-129.

Schwartz, J.J. \& Wells, K. D. (1984). Interspecific acoustic interactions of the neotropical frog, Hyla ebraccata. Behavioral Ecology and Sociobiology 14, 211-224.

Seehausen, O. \& Schluter, D. (2004). Male-male competition and nuptial color displacement as a diversifying force in Lake Victoria cichlid fish. Proceeding of the Royal Society of London B 271, 1345-1353.

Seehausen, O. \& Van Alphen, J. J. M. (1998). The effect of male coloration on mate choice in closely related Lake Victoria cichlids (Haplochromis nyererei complex). Behavioral Ecology and Sociobiology 42, 1-8.

Semple, S. (1998). The function of copulation calls in the Barbary macaque (Macaca sylvanus). Proceeding of the Royal Society of London B 265, 287-291.

Sih, A., Lauer, M. \& Krupa, J.J. (2002). Path analysis and the relative importance of male-female conflict, female choice and male-male competition in waterstriders. Animal Behaviour 63, 1079-1089. 
Simmons, L. W. (1991). Female choice and the relatedness of mates in the field cricket, Gryllus bimaculatus. Animal Behaviour 41, 493-501.

Simmons, L. W. (2001). Sperm Competition and its Evolutionary Consequences in the Insects. Princeton University Press, Princeton.

Sorenson, L. G. \& Derrickson, S. R. (1994). Sexual selection in the northern pintail (Anas acuta): the importance of female choice versus male-male competition in the evolution of sexually-selected traits. Behavioral Ecology and Sociobiology 35, 389-400.

Sparreboom, M. (1997). Sexual interference in the sword-tailed newt, Cynops ensicauda popei (Amphibia, Salamandridae). Ethology 103, 265.

Thiel, M. \& Correa, C. (2004). Female rock shrimp Rhynchocinetes typus mate in rapid succession up a male dominance hierarchy. Behavioral Ecology and Sociobiology 57, 62-68.

Thornhill, R. (1979). Male and female sexual selection and the evolution of mating strategies in insects. In Reproductive Competition and Sexual Selection (eds. M. Blum and N. Blum), pp. 81-121. Academic Press, New York.

Thornhill, R. (1980). Rape in Panorpa scorpionflies and a general rape hypothesis. Animal Behaviour 28, 52-59.

ThornhiLL, R. (1988). The jungle fowl hen's cackle incites male competition. Verhandlungen der Deutschen Zoologischen Gesellchaft 81, 145-154.

Torok, J., Hegyi, G. \& Garamszegi, L. Z. (2003). Depigmented wing patch size is a condition-dependent indicator of viability in male collared flycatchers. Behavioral Ecology 14, 382-388.

TraIL, P. W. (1985). Courtship disruption modifies mate choice in a lek-breeding bird. Science 227, 778-779.

Valone, T. J. \& Templeton, J. J. (2002). Public information for the assessment of quality: a widespread social phenomenon. Philosophical Transactions of the Royal Society of London B 357, 1549-1557.

van Doorn, G. S., Diekmann, U. \& Weissing, F.J. (2004). Sympatric speciation by sexual selection: a critical re-evaluation. American Naturalist 163, 709-725.

Vitjugrein, H. (1997). The cost of dishonesty. Proceedings of the Royal Society of London B 264, 815-821.
Warner, R. R., Shapiro, D. Y., Marcanato, A. \& Petersen, C. W. (1995). Sexual conflict - males with the highest mating success convey the lowest fertilization benefits to females. Proceedings of the Royal Society of London B 262, 135-139.

Webster, M. S. \& Robinson, S. K. (1999). Courtship disruptions and male mating strategies: examples from female-defense mating systems. American Naturalist 154, 717-729.

Wells, K. D. (1988). The effects of social interactions on anuran vocal behavior. In The Evolution of the amphibian Auditory System (eds. B. Fritszch, W. Wilczynski, M.J. Ryan, T. Hetherington and W. Walkowiak). Wiley, New York.

Wells, K. D. \& Schwartz, J. J. (1984). Vocal communication in a neotropical frog, Hyla ebraccata: advertisement calls. Animal Behaviour 32, 405-420.

Whitney, G. L. \& Krebs, J. R. (1975). Mate selection in Pacific treefrogs. Nature 255, 325-326.

Wikelski, M., Carbone, C. \& Trillmich, F. (1996). Lekking in marine iguanas: female grouping and male reproductive strategies. Animal Behaviour 52, 581-596.

Wiley, R. H. \& Poston, J. (1996). Indirect mate choice, competition for mates, and coevolution of the sexes. Evolution 50, 1371-1381.

Wollerman, L. (1999). Acoustic interference limits call detection in a neotropical frog Hyla ebraccata. Animal Behaviour 57, 529-536.

Wong, B. B. M. (2004a). Male competition is disruptive to courtship in the Pacific blue-eye fish. Fournal of Fish Biology 65, 333-341.

Wong, B. B. M. (2004b). Superior fighters make mediocre fathers in the Pacific blue-eye fish. Animal Behaviour 67, 583-590.

Wright, J. (1998). Paternity and paternal care. In Sperm Competition and Sexual Selection (eds. T. R. Birkhead and A. P. Moller), pp. 117-145. Academic Press, London.

ZAHAVI, A. (1975). Mate selection - a selection for a handicap. Fournal of Theoretical Biology 53, 205-214.

ZaHavi, A. (1977). The cost of honesty (further remarks on the handicap principle). Fournal of Theoretical Biology 67, 603-605.

ZAHAVI, A. (1987). The theory of signal selection and some of its implications. In International symposium of biological evolution (ed. V. P. Delfino), pp. 305-327. Adriatica Editrica, Bari. 